\title{
La cohesión legislativa entre la Concertación y el Partido Comunista en Chile, 2010-2013
}

\author{
Alexis Marambio,* Patricio Navia,** Cristian Figueras, ${ }^{* * *}$ \\ Ariel Madera****
}

Perfiles Latinoamericanos, 25(50)

2017 | pp. 179-202

DOI: $10.18504 / \mathrm{pl} 2550-009-2017$

\begin{abstract}
Resumen
Aunque el Partido Comunista de Chile (PC) llegó al Congreso en 2009 por un pacto electoral con la Concertación, no fue parte formal de esta coalición en el periodo legislativo 2010-2013. A pesar de esto cooperaron en varios ámbitos como oposición. Aquí evaluamos si esto incluyó el trabajo legislativo. Aplicando la teoría de principales en competencia a la adscripción partidista y de coalición que pudieran tener los diputados en Chile, analizamos la cohesión legislativa en la autoría de los 1284 proyectos de ley presentados durante ese periodo en la Cámara de Diputados. Si bien formaron un pacto electoral, la Concertación y el PC no se comportaron como pacto político en patrocinio de proyectos de ley (mociones). Aunque el PC está más cerca de la Concertación que de otros partidos, hay más distancia entre ese partido y los de la Concertación que al interior de esa coalición. También hay más distancia entre el PC y el Partido Demócrata Cristiano (PDC) que entre este y los partidos de derecha.
\end{abstract}

\begin{abstract}
Though it first won seats in the Chilean Congress in 2009 thanks to an electoral pact with the center-left Concertación, the Partido Comunista (PC) was not formally a member of the coalition in the 2010-2013 legislative period. As part of the opposition, there were instances of cooperation between the Concertación and the PC. We assess if that cooperation was also present in the legislative behavior. Applying the theory of competing principals to the party and coalition affiliation that Chilean legislators might have, we analyze the 1284 legislative bills introduced in the Chamber of Deputies in the period. Though they formed an electoral coalition, the Concertación and PC did not behave as a political coalition in terms of bill sponsorship. Though the PC is closer to the Concertación than to other parties, there is greater distance between the PC and Concertación parties than within the Concertación. There is also greater distance between the PC and the Partido Demócrata Cristiano (PDC) than between the PDC and rightwing parties.
\end{abstract}

Palabras clave: comportamiento legislativo, principales en competencia, cohesión legislativa, patrocinio de proyectos de ley, Partido Comunista, Chile, Concertación, Cámara de Diputados. Keywords: Legislative behavior, competing principals, legislative cohesion, bill sponsorship, Partido Comunista, Concertación, Chile, Chamber of Deputies.

* Universidad Diego Portales | alexis.marambio.91@gmail.com

** New York University/Universidad Diego Portales | patricio.navia@nyu.edu

*** Universidad Diego Portales | cristian.figueras.d@gmail.com

**** Universidad Diego Portales | arielmaderac@gmail.com 


\section{Introducción ${ }^{1}$}

E

las elecciones legislativas chilenas de 2009, la coalición centro-izquierdista Concertación formó un pacto electoral con el Partido Comunista (PC). Los cuatro partidos de aquella aspiraban a mantener el control del Ejecutivo y aumentar su número de legisladores electos, mientras que el segundo aspiraba, por primera vez, desde el retorno de la democracia en 1990, a obtener escańos en la Cámara de Diputados. El PC obtuvo tres diputados, pero la Concertación perdió el control del Ejecutivo y perdió once escaños respecto a 2005, alcanzando 54 de 120, lo que le significó perder el control de la Cámara. Para muchos, el pacto electoral Concertación/PC, con sus 57 escaños, devino en una coalición política de facto que se formalizó cuando la Concertación se renombró como Nueva Mayoría meses antes de su aplastante victoria electoral en 2013. Para otros, la Concertación y el PC no se comportaron como una coalición mientras estuvieron en la oposición. Utilizando la teoría de Carey de principales en competencia (competing principals) (Carey, 2007), analizamos la autoría de los 1284 proyectos de ley (mociones legislativas) de entre marzo de 2010 y diciembre de 2013 que presentaron los miembros de la Cámara de Diputados, esto con el fin de estimar el grado de cohesión ideológica de los diputados de los partidos Demócrata Cristiano (PDC), el Radical Social Demócrata (PRSD), el Socialista, el Por la Democracia (PPD) y el Comunista (PC). Evaluamos en específico si los diputados de este último se comportaron como miembros de una coalición multipartidista o de un partido autónomo.

\section{Principales en competencia: lealtad legislativa con partidos y coaliciones}

Las coaliciones pueden ser pre y poselectorales. Y estas últimas pueden ser de gobierno o de oposición. La formación de tales coaliciones se explica por incentivos tal vez asociados a las reglas electorales antes de la elección o al funcionamiento del Congreso después de la elección (Golder, 2006). Los incentivos de las reglas electorales afectan la formación de coaliciones preelectorales entre partidos con ideologías afines (Cox, 2004). Pero si las reglas pueden inducir a

1 Agradecemos a nuestros colegas del Observatorio Político Electoral de la Universidad Diego Portales (OBPE-UDP) y a los dos revisores anónimos por sus pertinentes y constructivas sugerencias. Este artículo fue parcialmente financiado por los proyectos Fondecyt Regular 1171051. Y por el proyecto Conicyt/ Fondap/15130009. Los errores u omisiones son de nuestra responsabilidad. 
que los partidos formen coaliciones preelectorales, los incentivos del funcionamiento del Congreso determinan si las mismas sobrevivirán después de la elección. Las coaliciones deberían estar integradas por un número mínimo de actores necesarios para gobernar (Colomer \& Martinez, 1995; Riker, 2001). La inclusión de un mayor número de integrantes en una coalición implica la reducción de las ganancias para cada actor. Las coaliciones ganadoras mínimas se pueden formar para ganar una elección o para construir mayorías en el Congreso (Golder, 2006).

En sistemas presidenciales, la formación de coaliciones legislativas mayoritarias a menudo no es requisito para gobernar. Mainwaring \& Shugart (1997) postulan que las coaliciones electorales en sistemas presidenciales se producen durante el proceso electoral, pero su formación no garantiza su consolidación como coalición de gobierno. De hecho, Mainwaring (1993) sostiene que el sistema presidencial no produce fuertes incentivos para que los partidos formen coaliciones. Es más, el sistema presidencial dificulta la búsqueda de cooperación entre los partidos. Pero Chasquetti (2001) argumenta que las coaliciones partidarias facilitan la gobernabilidad del presidente.

Destacando la importancia del funcionamiento de las instituciones, Alemán \& Tsebelis (2012) sostienen que presidentes que gobiernan con Congresos débiles no estarán presionados para formar coaliciones. Tsebelis (2002) caracteriza a los sistemas presidenciales como instancias en las que el Legislativo hace las propuestas y el presidente las apoya o veta. Por el contrario, Figueiredo \& Limongi (2000) afirman que en los sistemas presidenciales, como Brasil, el presidente controla los tiempos de la agenda a través de sus facultades legislativas. De ahí que, para entender los incentivos que existen para la formación de coaliciones poselectorales, hay que entender los incentivos de cada sistema institucional.

Al estudiar sistemas parlamentarios en Europa, Laver \& Shepsle (1996) se concentran en la forma en que las coaliciones se construyen a partir de la distribución de espacios de poder en el gabinete (cabinet allocation portfolio) y de espacios de influencia sobre las prioridades políticas y de políticas públicas en el gobierno. Laver \& Shepsle (1996) subrayan la cercanía ideológica de los partidos como una variable explicativa del éxito de las coaliciones mayoritarias. Extendiendo el argumento, el éxito de las coaliciones de oposición también es posible que se deba a la cercanía ideológica de sus miembros.

Un clásico análisis sobre el funcionamiento del Congreso estadounidense (Cox \& McCubbins, 2007, 2005) señala que el partido mayoritario funciona como un cártel legislativo que estructura las reglas de juego para solucionar los problemas de acción colectiva que emanan de la existencia de intereses particulares de los congresistas —o de sus distritos — y de la necesidad de coordinar para avanzar los intereses del partido. A partir de esa teoría, Carey (2007) postula 
que los legisladores enfrentan un desafío al tener que rendir cuentas a dos mandantes (o principales). Por un lado, los legisladores se deben a sus distritos y por otro a sus partidos. Cuando los intereses de sus electores difieren de los de sus partidos, los legisladores privilegian los intereses que más optimicen su probabilidad de ser reelectos o de avanzar en sus carreras políticas.

Con el mismo argumento podemos suponer que los legisladores se deben a los partidos a los que pertenecen, pero también a las coaliciones con las que obtuvieron sus escaños. Si bien los legisladores militan en partidos con los que comparten ideología, consiguieron sus cargos porque sus partidos formaron coaliciones preelectorales que les permitieron ser candidatos. Esos legisladores de un partido $\mathrm{X}$ pudieron recibir remanentes de votos de sus compañeros de lista de otros partidos o, en algunos casos, votos de electores que simpatizaban más con otros partidos de la coalición que se omitieron en esos distritos para apoyar a los candidatos del partido X. De ahí que resulte razonable sugerir que los competing principals pueden asociarse a los distritos que representan los legisladores, a los partidos en los que militan los legisladores y a las coaliciones electorales que permitieron a esos legisladores ganar sus escaños.

En América Latina, los estudios legislativos popularizados luego de la década de 1990 han utilizado el modelo de Cox y McCubbins para entender el funcionamiento de los partidos y la formación de coaliciones (Carey, 2002). Crisp et al. (2004) analizan el comportamiento de los legisladores en proyectos de ley en democracias latinoamericanas, estableciendo que ellos actúan respecto a las normas electorales, la carrera del legislador y las relaciones interprofesionales. Algunas contribuciones se han focalizado en la aprobación de los copatrocinios (Blofield \& Haas, 2005; Crisp et al., 2004) y en la influencia de los partidos mayoritarios (Rocca \& Sanchez, 2007; Figueiredo \& Limongi, 2000).

Los estudios del comportamiento del Legislativo chileno utilizan un marco teórico similar para reportar las dinámicas que se presentan tanto para el periodo pre 1973 como para el periodo democrático post 1990. Blofield \& Haas (2005), estudiando proyectos de ley que expanden los derechos de las mujeres en Chile, reportan que los proyectos de ley que provienen del Ejecutivo tienen más éxito que los que emanan del Legislativo. Alemán \& Calvo encontraron que la probabilidad de que los legisladores chilenos patrocinaran proyectos de ley en conjunto dependía de su militancia, pero también de que representaran distritos vecinos o que fueran miembros de la misma comisión (Alemán $\&$ Calvo, 2013). Al mostrar que en el periodo post 1990 hay fuertes lazos entre legisladores de distintos partidos, y de distintas coaliciones, en el patrocinio de mociones, Alemán destaca los incentivos institucionales que existen para inducir la cooperación en el Congreso chileno (Alemán, 2009). En un estudio sobre el comportamiento legislativo en el periodo post 1990, Alemán \& Saiegh 
confirman la existencia de dos coaliciones no centristas, una de izquierda y otra de derecha, en torno a la que se ordena el comportamiento de los legisladores (Aleman \& Saiegh, 2007). Evaluando el comportamiento de los legisladores en sus votaciones en sala (roll call), Toro reportó un alto nivel de disciplina tanto en los partidos del oficialismo como en los de la oposición (Toro, 2007).

La evidencia existente en el caso de Chile destaca la disciplina de las coaliciones de gobierno y la opositora. Pero ya que hasta 2010 la coalición de gobierno siempre fue la Concertación y la coalición de oposición siempre fue la Alianza, el cambio de coalición en el poder que se produjo a partir de marzo de 2010 permite evaluar si la disciplina del oficialismo se debió a su condición de oficialista o a la identificación de centro-izquierda de sus partidos. A su vez, que el pc llegara a la Cámara de Diputados en 2009, como parte de un acuerdo electoral con la Concertación, permite evaluar si, a partir de que la Concertación y el PC pasaron a formar parte de la oposición, ese acuerdo electoral devino en una coalición opositora que, siguiendo la tradición chilena, se comportó disciplinadamente en su conducta legislativa.

Para responder a esa pregunta, analizamos los copatrocinios de proyectos de ley presentados por los diputados entre 2010 y 2013, y evaluamos la cohesión legislativa de la oposición. Nuestra hipótesis es que, en su comportamiento en patrocinio de mociones, los diputados de la Concertación y del PC se comportaron como parte del mismo partido/coalición. Esto es, que ambos tipos de diputados respondían a la misma dinámica de principales en competencia, con lo que se hacían cargo tanto de las preferencias de sus votantes como de su adscripción a su coalición. Si bien los diputados también responden a las preferencias de sus partidos; como pertenecen a una misma coalición comparten un mismo principal.

\section{Contexto de Chile}

Primero presentamos la historia previa de acercamientos y diferencias entre la Concertación y el PC en el periodo anterior a 2010. Durante la dictadura (1973-1990), y especialmente poco antes del plebiscito de 1988, existieron discrepancias entre el PC y el resto de la oposición democrática respecto a cómo se debía inducir el regreso de la democracia. A comienzos de los ochenta, el Partido Demócrata Cristiano (PDC), junto a facciones del Partido Socialista (PS), formaron la Alianza Democrática (AD), coalición predecesora de la Concertación que buscaba una transición pacífica a la democracia. Por su parte, el PC junto a otros grupos de izquierda formó el Movimiento Democrático Popular (MDP) que promovía la caída del régimen militar. La forma en que se produjo la transición favoreció la estrategia de los moderados. La Concertación 
lideró la campaña contra Pinochet en el plebiscito, aceptando que la transición se daría bajo el contexto establecido por la Constitución de 1980. Si bien semanas antes del plebiscito de 1988, el pc llamó a votar contra Pinochet, la tardía decisión de ese partido evidenció una distancia con la Concertación que se mantuvo hasta finalizada la dictadura.

Después de la derrota de Pinochet en el plebiscito, la Concertación devino en una coalición electoral que ganó la elección presidencial y legislativa de 1989. Las tensiones por las estrategias distintas de los partidos de la Concertación y el PC en la transición a la democracia dificultaron que se formara una coalición única de centro-izquierda en la primera elección democrática de 1989 y en las contiendas posteriores. El sistema electoral que estableció la dictadura, llamado binominal, incentivaba a que los partidos se agruparan en dos grandes coaliciones y dificultaba que una tercera fuerza electoral consiguiera representación legislativa, puesto que producía altas barreras de entrada - con un tercio más uno de los votos se garantiza un escaño- - y favorecía a la segunda lista más votada (Siavelis, 2005; Navia, 2005). Entre 1989 y 2005, el sistema binominal impidió que el PC, que se presentaba en una lista por fuera de la Concertación, ganara escańos.

Ya en el poder, la Concertación se consolidó como una coalición política, en tanto el PC mantenía una posición distante del gobierno concertacionista. Esa distancia se mantuvo durante el gobierno del concertacionista Eduardo Frei (1994-2000), periodo en el que el PC fue sindicado como líder de la izquierda extraparlamentaria, para distinguirla de la izquierda concertacionista.

Aunque hubo algunos intentos de acercamiento con la Concertación, las propias críticas del PC a lo que consideraba una democracia tutelada, y la resistencia del PDC a aceptar el ingreso del PC a la coalición, dificultaron los acuerdos. Debido a los incentivos del sistema binominal, existían incentivos para un acuerdo Concertación-PC. Si este último se abstenía de presentar candidatos en algunos distritos, aumentaba la probabilidad de que la Concertación obtuviera más escaños. A su vez, la Concertación podría, a cambio de esas omisiones del PC, prescindir en otros distritos donde este podía lograr escaños. Pero la coalición electoral nunca se materializó. Un símbolo de ese fracaso fue la elección de senadores en Santiago Poniente en 1997, cuando los candidatos del ps Camilo Escalona (16\%) y del PC Gladys Marín (15.7\%), compitiendo en listas opuestas, dividieron la votación de la izquierda, quedando ambos sin escaños.

Después que los candidatos presidenciales de la Concertación, Patricio Aylwin y Eduardo Frei, ganaron con mayoría absoluta en 1989 y 1993, respectivamente, en 1999 el candidato de la Concertación y proveniente del Partido por la Democracia (PPD), Ricardo Lagos, solo alcanzó el 48\% de los votos, rebasando apenas el 47.5\% logrado por el candidato de derecha Joaquín Lavín. El PC, que había presentado su propia candidata presidencial —Gladys Marín, 
la secretaria general del partido e influyente líder de las posiciones más radicales-y que terminó en tercer lugar con un 3.3\%, anunció que anularía su voto en segunda vuelta. Pero, presumiblemente, una mayoría de sus votantes apoyaron a Lagos en la segunda vuelta.

En el gobierno de Lagos (2000-2006), primer mandatario de izquierda desde Allende, aumentaron los acercamientos Concertación-PC. El gobierno consiguió restituir a los partidos políticos existentes en 1973 las propiedades que les habían sido confiscadas por la dictadura, decisión que benefició al PC. Si bien ningún militante del PC se incorporó al gobierno de Lagos, las relaciones con La Moneda mejoraron. La muerte de Marín, en marzo de 2005, permitió al gobierno realizar gestos simbólicos hacia la fallecida y el PC por su contribución a la recuperación de la democracia.

Aunque no hubo un pacto electoral explícito, después del acercamiento en la segunda vuelta de enero de 2000, "se sucedieron pactos instrumentales para todas las elecciones [presidenciales] venideras" (Contreras, Espinoza \& Perelló, 2012, 227). En las elecciones legislativas de 2005, el pc lideró la coalición Juntos Podemos Más, que obtuvo el 7.4\%, aunque no logró la elección de diputados. El PC recibió un $5.1 \%$. Tres de sus 62 candidatos recibieron más de un $10 \%$ de votación en sus distritos, lo que demostró una fuerza electoral que hacía atractiva una coalición con la Concertación.

En la contienda presidencial de 2005, el candidato del pc fue el humanista Tomás Hirsch (5.4\%), cuya votación estuvo muy por detrás de la candidata de la Concertación y que militaba en el ps, Michelle Bachelet (46\%). La suma de la votación de los dos candidatos presidenciales de derecha fue de $48.6 \%$, lo que obligó a la Concertación a buscar el apoyo del PC en segunda vuelta. Aunque Hirsch se negó, el pc llamó a votar por Bachelet, quien se impuso con 53.5\%. El apoyo del PC estuvo condicionado a que Bachelet se comprometiera con una serie de reformas, incluido el cambio del sistema electoral. El hecho de que la Concertación y el PC llegaran a un acuerdo formal sentó las bases del pacto electoral Concertación-PC de 2008.

En 2008, el PC prescindió de llevar candidatos a alcalde en diecisiete comunas, mientras que la Concertación hizo lo mismo en ocho casos. De las diecisiete donde el PC omitió candidaturas, la Concertación ganó en seis, pero tres de estas ya pertenecían a la Concertación en 2004. Al llevar menos candidatos, la votación del PC en alcaldes bajó de 3\% en 2004 a 2.5\% en 2008. Pero el PC mantuvo tres de sus cuatro alcaldías y ganó la de Pedro Aguirre Cerda, una comuna de la Región Metropolitana — simbólica porque allí está la conocida población La Victoria.

Un año después, en los comicios presidenciales de 2009, la posibilidad de un pacto entre la Concertación y el PC se vio frustrada, aunque se materializó 
otro en la elección legislativa. En la derecha, la Alianza presentó como candidato a Sebastián Piñera, quien ya había perdido estrechamente en 2005. La centroizquierda, en cambio, presentó tres candidatos presidenciales. La Concertación presentó al expresidente Eduardo Frei. Además, compitió como independiente el exdiputado del ps, Marco Enríquez-Ominami. El pC proclamó a Jorge Arrate, exministro de gobiernos concertacionistas. Piñera logró la primera mayoría, pero debió ir a segunda vuelta contra Frei. Enríquez-Ominami alcanzó un sorpresivo 20.1\% mientras que Arrate llegó al 6.2\%. En segunda vuelta, la Concertación recibió el apoyo explícito de Arrate y del PC - y un apoyo menos decidido de Enríquez-Ominami-. Piñera se impuso con el 51.6\%.

En las elecciones legislativas de 2009, simultáneas a la presidencial, la Concertación y el PC consensuaron un pacto contra la exclusión. Los resultados de las elecciones de diputados dan cuenta del éxito de la estrategia de acercamiento, en especial para el PC. Este disminuyó su votación respecto a 2005, de 5.1\% pasó a $2 \%$, pero logró la elección de tres de sus nueve candidatos: Hugo Gutiérrez, Lautaro Carmona y Guillermo Teillier fueron electos en los distritos 2, 5 y 28 , respectivamente.

Según Contreras et al. (2012), la estrategia del PC de acercarse a la Concertación respondió a cambios en el liderazgo del partido. Después del retorno de la democracia, el histórico secretario general del PC, Luis Corvalán (1958-1990), fue remplazado por Volodia Teitelboim, quien lideró el partido entre 1990 y 1992. Gladys Marín se convirtió en secretaria general hasta su muerte en 2005. Si bien su liderazgo se vio mermado a partir de 2003, cuando fue diagnosticada con cáncer, Marín se mantuvo en el cargo hasta su muerte. En 2005, asumió Guillermo Teillier, quien había estado involucrado en la resistencia armada contra la dictadura. Teillier privilegió una posición de diálogo con los partidos de la Concertación. El avance desde el aislamiento político a comienzos de los noventa a una política de coaliciones permitió que el PC recuperara representatividad e influencia. En marzo de 2010, por primera vez en democracia postautoritaria, asumió el poder un gobierno de centro-derecha. Además, también por primera vez, el PC tuvo representación en la Cámara con tres diputados.

\section{La Concertación y el PC en el gobierno de Piñera}

Piñera (marzo de 2010-marzo de 2014) se convirtió en el primer presidente de derecha democráticamente electo desde el regreso de la democracia. A su vez, la Concertación se encontró por primera vez como oposición. En un inicio, la unidad de la coalición centro-izquierdista pareció romperse. Pero las protestas estudiantiles de 2011, junto a la caída en la popularidad de Piñera, facilitaron 
la unidad de la oposición en torno a su rechazo a las políticas oficialistas. Para las elecciones municipales de 2012, y en tanto las encuestas mostraban el favoritismo de la expresidenta Bachelet para las presidenciales de 2013, los partidos opositores se unieron en apoyo a una eventual candidatura presidencial de Bachelet. Luego, aunque discreparan en cuestiones valóricas - con un PDC más conservador y una izquierda más liberal — y su evaluación sobre la economía social de mercado - con sectores de izquierda más críticos del modelo anteriormente promovido por los gobiernos concertacionistas-, la Concertación y el PC se unieron en sus críticas al gobierno y en el intento por construir una alternativa de centro-izquierda.

Durante el cuatrienio de Piñera, en cada contienda electoral la Concertación y el PC profundizaron su acuerdo electoral. Como lo muestra el cuadro 1, en las municipales de 2012 la Concertación se dividió en dos listas, igual que en 2008. Una de las listas, Por un Chile Justo, se componía del PPD, el PRSD y el PC, con candidatos en 112 comunas. Ese año el PC presentó candidatos a alcaldes en siete comunas, y ganó en cuatro, con un total de 74997 votos (1.4\%).

Cuadro 1. Resultados para alcaldes de la Concertación, elecciones municipales 2012

\begin{tabular}{llrrrr}
\hline Lista & Partido & Total votos & \% votos & Candidatos & Electos \\
\hline \multirow{4}{*}{ Concertación Democrática } & PDC & 915044 & 16.51 & 120 & 56 \\
& PS & 547102 & 9.87 & 70 & 30 \\
& Independientes & 169560 & 3.05 & 35 & 20 \\
& Total & 1631706 & 29.44 & 225 & 106 \\
\hline \multirow{5}{*}{ Por un Chile Justo } & PPD & 362649 & 6.54 & 61 & 37 \\
& PRSD & 182592 & 3.29 & 27 & 13 \\
& PC & $\mathbf{7 4 9 9 7}$ & $\mathbf{1 . 3 5}$ & $\mathbf{7}$ & $\mathbf{4}$ \\
& Independientes & 133234 & 2.40 & 17 & 7 \\
\hline Ambas listas & Total & 753472 & 13.59 & 112 & 61 \\
\hline
\end{tabular}

Fuente: Elaboración propia con datos del Servicio Electoral (Servel). Recuperado de http://www.elecciones.gov.cl

Cuadro 2. Resultados para concejales de la Concertación, elecciones municipales 2012

\begin{tabular}{llrrrr}
\hline Lista & Partido & Total votos & \% votos & Candidatos & Electos \\
\hline \multirow{2}{*}{$\begin{array}{l}\text { Concertación } \\
\text { Democrática }\end{array}$} & PDC e indep. & 804622 & 15.07 & 1095 & 391 \\
& PS e indep. & 653611 & 12.24 & 1031 & 269 \\
& Total & 1458233 & 27.31 & 2126 & 660 \\
\hline \multirow{2}{*}{ Por un Chile Justo } & PPD e indep. & 528974 & 9.90 & 793 & 277 \\
& PRSD e indep. & 304408 & 5.70 & 718 & 126 \\
& PC+ y aliados & $\mathbf{3 4 2 0 6 2}$ & $\mathbf{6 . 4 0}$ & $\mathbf{5 7 4}$ & $\mathbf{1 0 5}$ \\
& Total & 1175444 & 22.01 & 2058 & 508 \\
\hline Ambas listas & & 2633677 & 49.32 & 4148 & 1168 \\
\hline
\end{tabular}

Fuente: Elaboración propia con datos del Servicio Electoral (Servel). Recuperado de http://www.elecciones.gov.cl 
El cuadro 2 muestra los resultados para la elección de concejales en 2012. El pC, la Izquierda Cristiana (IC) y sus independientes, en conjunto consiguieron la elección de 105 concejales de sus 574 candidatos. Asimismo, los votos recibidos por estas colectividades correspondieron a 342062 (6.4\%) votos.

Los resultados de la elección municipal fueron favorables para la Concertación, que logró 167 alcaldes, superando ampliamente los 122 de la Alianza. Pero el hecho de que una de las dos coaliciones en las que se dividió la Concertación ya no usara el emblemático nombre anticipaba el cambio que eventualmente se produciría.

Para las elecciones de 2013, la Concertación y el PC forjaron un nuevo pacto que, con el apoyo de la candidata presidencial, la expresidenta Bachelet, adoptó el nombre de Nueva Mayoría (NM). En las primarias presidenciales del mes de junio, Bachelet ganó fácilmente la nominación de la NM como candidata apoyada por el PC, entre otros partidos. En primera vuelta, Bachelet obtuvo un $46.7 \%$ de los votos. En la segunda vuelta de diciembre de 2013, Bachelet recibió un $62.2 \%$, la cifra más alta recibida por un candidato presidencial desde el retorno de la democracia.

En las elecciones legislativas, de los 120 escaños en la Cámara de Diputados, la NM ganó 67, superando ampliamente los 49 de la Alianza. En el Senado, la NM obtuvo doce de los veinte escańos en disputa, alcanzando una mayoría de 21 entre 38 escaños. Como partido integrante de esta coalición, el PC participó de la victoria con seis diputados, duplicando así su presencia en la Cámara.

Si bien la estrategia electoral resultó un éxito para el PC y la Concertación en 2013, el hecho de que el PC haya llegado al Congreso ya en 2010 a través de un pacto electoral con la Concertación lleva a pensar que la formación de la NM fue solo la materialización de un acuerdo que se gestó en 2009 y, presumiblemente, se materializó en el comportamiento de los partidos de la Concertación y del PC durante el gobierno de Piñera. En lo que sigue, evaluamos si eso efectivamente ocurrió en el comportamiento de los diputados de la Concertación y del PC durante el cuatrienio 2010-2014.

\section{La Concertación y el PC en la Cámara de Diputados, 2010-2014}

El Congreso Nacional está conformado por la Cámara de Diputados y el Senado. La Cámara está integrada por 120 miembros electos de manera directa en sesenta distritos de dos escaños cada uno, y se renueva cada cuatro años. En el periodo 2010-2014, la Cámara tuvo 25 comisiones permanentes (a excepción de 2012 cuando hubo 26). La presidencia de las comisiones se determina por mayoría de los miembros en ejercicio. Tradicionalmente, la coalición mayoritaria 
ha entregado la presidencia de algunas comisiones a las coaliciones minoritarias. Normalmente, las presidencias de las comisiones rotan de año en año. En el periodo 2010-2014, hubo 101 presidencias diferentes en las 25 comisiones (26 comisiones en 2012). La Alianza presidió 63 comisiones y la Concertación 34 , dos de las cuales fueron encabezadas por el PC.

El cuadro 3 muestra la presencia en comisiones de los tres diputados del PC entre marzo de 2010 y marzo de 2014. En este periodo, Lautaro Carmona presidió la comisión de Superación de la Pobreza, Planificación y Desarrollo Social en 2011, además fue integrante de la comisión de Minería y Energía. Hugo Gutiérrez fue presidente de la comisión de Derechos Humanos, Nacionalidad y Tecnología en 2010, y participó en las comisiones de Ciencia y Tecnología, Comisión Revisora de Cuentas y Zonas Extremas. Guillermo Teillier ha participado en las comisiones de Recursos Naturales, Bienes Nacionales y Medioambiente, Relaciones Exteriores, Asuntos Interparlamentarios e Integración Latinoamericana, y Micro, Pequeña y Mediana Empresa. Ninguno de los tres diputados del PC presidió una comisión en 2012 o 2013.

Cuadro 3. Diputados del PC en comisiones de la Cámara de Diputados, 2010-2013

\begin{tabular}{llll}
\hline & Carmona & Gutiérrez & Teillier \\
\hline \multirow{2}{2010-2013}{} & Superación de la Pobreza, & Derechos Humanos & Recursos Naturales \\
& Planificación y Desarrollo & Nacionalidad y Tecnología & Bienes Nacionales y Medioambiente \\
Social (Presidente en 2011) & (Presidente en 2010) & Relaciones Exteriores, Asuntos \\
& Minería y Energía & Ciencia y Tecnología & Interparlamentarios e Integración \\
& Zonas Extremas & Latinoamericana \\
& Comisión Revisora de Cuentas & Micro, Pequeña y Mediana Empresa \\
\hline
\end{tabular}

Fuente: Elaboración propia con información de http://www.camara.cl/

Si bien la presencia de los diputados del PC en comisiones resultó de una negociación con los partidos de la Concertación, el comportamiento legislativo de aquellos no tenía por qué responder a la misma lógica de negociación que se produjo al asignar membresía y presidencia en comisiones. Para evaluar el comportamiento de los diputados del PC y sus pares de la Concertación, y analizar si efectivamente lo hicieron como miembros de la misma coalición, procedemos a evaluar los patrocinios de mociones legislativas realizadas durante el periodo 2010-2014.

\section{Cohesión legislativa en el patrocinio de mociones de la Concertación y el PC}

Para evaluar si los partidos de la Concertación y el PC se comportaron como una coalición política —y no solo electoral— durante el cuatrienio de Piñera, evalua- 
mos el comportamiento de los diputados de la Concertación y del PC en la presentación de proyectos de ley (patrocinio de mociones) en el periodo. Por cierto, los proyectos de ley discutidos en el Congreso pueden provenir desde el Ejecutivo o desde los legisladores. Aquellos que provienen del primero se denominan mensajes, mientras que los que emanan desde los legisladores se denominan mociones. Las mociones pueden ser iniciadas en la Cámara o en el Senado, y requieren la firma de un máximo de diez diputados o cinco senadores (Artículo $65^{\circ}$ ).

Estudiamos la cohesión ideológica de los partidos políticos a partir de la autoría de proyectos de ley presentados como mociones por miembros de la Cámara de Diputados. Analizamos 1284 mociones presentadas por los diputados entre marzo de 2010 y diciembre de $2013 .^{2}$ Además de la Alianza (58 diputados) y la Concertación (58, incluidos los tres del PC), consideramos a cuatro diputados de otras coaliciones e independientes. Ese grupo incluye a dos diputados del Partido Regionalista Independiente (PRI) (formado por exconcertacionistas que abandonaron el PDC a comienzos de 2008) y a dos independientes. Cabe acotar que el diputado Luis Lemus, electo por el PRI, volvió al Ps poco después de asumir su cargo, por lo que lo analizamos como parte de este segundo partido.

Tenemos dos razones para optar por analizar el patrocinio de proyectos de ley en vez de las votaciones que realizan los legisladores sobre los proyectos de ley que se tramitan. Primero, porque solo hay tres diputados del PC $(2.5 \%$ del total de la Cámara), por lo que, si quisiéramos evaluar la cohesión ideológica de los legisladores del PC respecto a los otros partidos, encontraríamos grandes distorsiones. Bastaría con que algún diputado del PC se ausentara de una votación para distorsionar la postura del partido en cuanto a algún tema. Segundo, como las votaciones en Sala a menudo reflejan negociaciones entre partidos o cuestiones procedimentales en la tramitación de una ley, las diferencias ideológicas entre los partidos no siempre se manifiestan adecuadamente. En cambio, al analizar los proyectos de ley que patrocinan distintos legisladores, podemos identificar claramente las posiciones ideológicas de los miembros de los distintos partidos. Porque un legislador solo presenta proyectos de ley con los que está de acuerdo - a diferencia de sus votos, que a veces reflejan acuerdos partidistas—, las diferencias ideológicas entre los partidos quedan mayormente manifiestas en el patrocinio de proyectos de ley.

Como se observa en el cuadro 4, en 2010 se presentaron 279 mociones y en 2011, fueron 405. En 2012 se presentaron 390 mociones y en 2013, 210. En

2 El periodo legislativo va de marzo de 2010 a marzo de 2014. Pero como las elecciones para el periodo siguiente se realizan en noviembre y diciembre de 2013, y el Congreso entra en receso en febrero, ignoramos los últimos dos meses del periodo legislativo (de enero al 10 de marzo de 2014) porque casi no se presentan mociones en ese periodo. 
promedio, las mociones son patrocinadas por ocho diputados, aunque hay un número no despreciable de mociones que alcanzan el máximo de diez patrocinios y otras que son patrocinadas por una cantidad sustancialmente menor.

Cuadro 4. Número de mociones presentadas en la Cámara de Diputados, 2010-2013

\begin{tabular}{lccc}
\hline Año & Número de mociones & Promedio de patrocinadores & Desviación estándar \\
\hline 2010 & 279 & 7.48 & 2.61 \\
2011 & 405 & 8.62 & 2.22 \\
2012 & 390 & 8.44 & 2.55 \\
2013 & 210 & 8.31 & 2.05 \\
Total & 1284 & 8.11 & 2.61 \\
\hline
\end{tabular}

Fuente: Elaboración propia con datos de la Biblioteca del Congreso (SIL).

Cuadro 5. Diputados que más mociones patrocinan y patrocinios de diputados del PC, 2010-2013

\begin{tabular}{lcccc}
\hline Diputado & Partido & $\begin{array}{c}\text { Número de } \\
\text { mociones }\end{array}$ & $\begin{array}{c}\text { \% de todas las } \\
\text { mociones }\end{array}$ & $\begin{array}{c}\text { Número promedio } \\
\text { de copatrocinadores }\end{array}$ \\
\hline Hasbún, Gustavo & UDI & 198 & 15.4 & 8.2 \\
Zalaquett, Mónica & UDI & 178 & 13.9 & 7.9 \\
Sepúlveda, Alejandra & PRI & 163 & 12.7 & 7.9 \\
Hoffman, María José & UDI & 155 & 12.1 & 8.2 \\
Pérez Lahsen, Leopoldo & RN & 151 & 11.8 & 8.1 \\
Hernández, Javier & UDI & 150 & 11.7 & 8.5 \\
Molina, Andrea & UDI & 147 & 11.5 & 8.3 \\
Morales, Celso & UDI & 147 & 11.5 & 8.5 \\
De Urresti, Alfonso & PS & 144 & 11.2 & 7.9 \\
Sandoval, David & UDI & 138 & 10.8 & 8.5 \\
Lautaro Carmona & PC & $\mathbf{8 9}$ & $\mathbf{6 . 9}$ & $\mathbf{7 . 4}$ \\
Hugo Gutiérrez & PC & $\mathbf{7 4}$ & $\mathbf{5 . 8}$ & $\mathbf{7 . 1}$ \\
Guillermo Teillier & PC & $\mathbf{9 1}$ & $\mathbf{7 . 1}$ & $\mathbf{7 . 8}$ \\
Promedio de diputados del PC & PC & $\mathbf{8 4 . 7}$ & $\mathbf{6 . 6}$ & $\mathbf{7 . 4}$ \\
Promedio de los 120 diputados & & 86.8 & $\mathbf{- - -}$ & 8.1 \\
\hline
\end{tabular}

Fuente: Elaboración propia con datos de la Biblioteca del Congreso (SIL).

El cuadro 5 muestra a los diez diputados que más mociones copatrocinaron y el número de mociones patrocinadas por los diputados del PC. Siete de los diputados más prolíficos pertenecen a la UDI. El diputado de la UDI, Gustavo Hasbún, copatrocinó 198 mociones (con un promedio de 8.24 copatrocinadores por moción), participando en un $15.4 \%$ del total de mociones para dicho periodo. La diputada de la UDI, Mónica Zalaquett, ocupa el segundo lugar con patrocinios en 178 mociones (13.9\%), con un promedio de 7.9 copatrocinadores. La sigue la diputada del PRI, Alejandra Sepúlveda, con 163 mociones (12.7\%) y 7.9 
copatrocinadores en promedio. Leopoldo Pérez de RN participó en 151 mociones (11.8\%). Javier Hernández (UDI) presentó 150 mociones (11.7\%).

Los tres diputados del PC aparecen con un promedio de 84.7 mociones. Teillier es el más activo (91 mociones), mientras que el diputado por Iquique, Hugo Gutiérrez, fue el menos activo del partido (74 mociones). En todo caso, Gutiérrez de todos modos patrocinó más mociones que otros 49 diputados en el periodo. Así, en promedio, los diputados del PC se ubican por sobre la media de patrocinios individuales en el periodo.

El cuadro 6 muestra las distintas combinaciones de patrocinios partidistas en las 1284 mociones del periodo. Estos datos permiten ver las conexiones que se produjeron entre diputados de distintos partidos en los patrocinios. Aunque tenía el mismo número de diputados que la Concertación, la Alianza patrocinó más mociones. Las 428 patrocinadas exclusivamente por diputados de la Alianza representan el 33.4\% del total. Los diputados de la Concertación patrocinaron en solitario $11.1 \%$ de las mociones. En el $55.3 \%$ de estas, hubo patrocinios de diputados de distintas coaliciones.

Cuadro 6. Copatrocinio de mociones por coalición

\begin{tabular}{llll|rr}
\hline \multicolumn{3}{c|}{ Coaliciones patrocinadoras } & Total & $\%$ \\
\hline PC & \multicolumn{1}{c}{ Concertación } & Alianza & PRI y otros & & \\
\hline PC & Concertación & Alianza & PRI y otros & 53 & 4.1 \\
PC & & & 3 & 0.2 \\
PC & Concertación & & & 51 & 4.0 \\
PC & Concertación & Alianza & & 59 & 4.6 \\
PC & Alianza & PRI y otros & 0 & 0 \\
PC & Alianza & & 2 & 0.2 \\
PC & & PRI y otros & 0 & 0 \\
PC & Concertación & PRI y otros & 31 & 2.4 \\
& Concertación & Alianza & PRI y otros & 157 & 12.2 \\
& Concertación & Alianza & & 290 & 22.6 \\
& Concertación & & PRl y otros & 53 & 4.1 \\
& Concertación & & & 143 & 11.1 \\
& & Alianza & PRI y otros & 13 & 1.0 \\
& & Alianza & & 428 & 33.3 \\
& & & PRl y otros & 1 & 0.1 \\
Total & & & 1284 & 100.0 \\
\hline
\end{tabular}

Fuente: Elaboración propia con datos de la Biblioteca del Congreso (SIL).

El PC ha participado en 199 mociones (15.5\%). De estas, en 51 oportunidades algún diputado del PC copatrocinó junto a legisladores de la Concertación, esto es, la coalición política con la que más patrocinan. Diputados del 
PC patrocinaron en solitario tres mociones. En 59 casos, las mociones fueron patrocinadas por diputados del PC, la Concertación y la Alianza. En otros 53 casos, las mociones fueron patrocinadas por todos los sectores.

El cuadro 6 muestra que hubo poca interacción en el patrocinio de mociones entre diputados del PC y de la Alianza. Si bien en 112 casos hubo coincidencias en los patrocinios, en todos ellos hubo también patrocinadores diputados de la Concertación. El PC actuó en forma autónoma de la Concertación copatrocinando mociones con la Alianza solo en dos casos en cuatro ańos.

El cuadro 7 muestra la presentación de mociones por año y por partido político. Asumimos la presencia de un partido cuando al menos un diputado de ese partido copatrocina una moción. Por eso, el total de mociones es superior a 1284, ya que una moción puede ser patrocinada por diputados de más de un partido. En total, hay 3945 patrocinios de partidos en las 1284 mociones presentadas en el periodo.

Los tres diputados del PC han copatrocinado en 199 ocasiones, y representan un $5 \%$ de todos los patrocinios posibles (3945). Considerando que el PC representa solo el $2.5 \%$ de los escaños de la Cámara, ese partido tuvo una participación en copatrocinios mayor que su peso relativo. El resto de los partidos, por su mayor número de diputados, ha participado en más copatrocinios. El ps ha participado en 495 (12.5\%). El PPD presentó 636 (16.1\%), el PRSD hizo lo propio con 319 (8.1\%). El PDC es el segundo partido que más patrocinios tuvo, 650 (16.5\%). RN participó en 550 (13.9\%). Mientras que la UDI es el partido que más patrocinó con 788 (20\%). El PRI/Independientes sumaron 308 (7.8\%) mociones.

Cuadro 7. Patrocinios de mociones por partidos

\begin{tabular}{lcccccr}
\hline Partido & 2010 & 2011 & 2012 & 2013 & \multicolumn{1}{c}{ Total } & Total \% (2010-13) \\
\hline PC & 39 & 70 & 59 & 31 & 199 & 5.0 \\
PS & 100 & 173 & 131 & 91 & 495 & 12.5 \\
PPD & 126 & 201 & 189 & 120 & 636 & 16.1 \\
PRSD & 69 & 104 & 95 & 51 & 319 & 8.1 \\
PDC & 123 & 212 & 193 & 122 & 650 & 16.5 \\
RN & 106 & 173 & 176 & 95 & 550 & 13.9 \\
UDI & 153 & 252 & 248 & 135 & 788 & 20.0 \\
PRI/Ind. & 53 & 104 & 92 & 59 & 308 & 7.8 \\
Total & 769 & 1289 & 1183 & 704 & 3945 & 100 \\
\hline
\end{tabular}

Fuente: Elaboración propia con datos de la Biblioteca del Congreso (SIL).

Para entender la formación de redes de patrocinios, identificamos todos los pares de copatrocinios posibles en las 1284 mociones. Así, si una moción fue patrocinada por cuatro diputados, identificamos los seis pares de patrocinios 
dados en esa moción. El cuadro 8 muestra el copatrocinio entre diputados de los diferentes partidos respecto al total de pares de copatrocinios observados. Existen 10493 pares de copatrocinios. De ellos, el 1.9\% fueron copatrocinados solo por pares de congresistas del PC. En el 0.9\% de todos los copatrocinios, hubo diputados del PC y de la UDI participando en conjunto. Como muestra el cuadro 8, el PC tuvo una mayor interacción en patrocinios con diputados de los partidos de la Concertación (PDC, PRSD, PPD y PS). De ellos, el PC parece levemente más cercano al ps en sus patrocinios, en tanto el 1.5\% de todos los pares de copatrocinios que existieron fueron entre diputados del PC y del PS.

Cuadro 8. Copatrocinios entre diputados de partidos respectivos respecto al total de pares de copatrocinios, 2010-2013

\begin{tabular}{lccccccccc}
\hline & UDI & $R N$ & $\begin{array}{c}P R I \\
\text { \&Ind }\end{array}$ & $P D C$ & $P R S D$ & $P P D$ & $P S$ & $P C$ & $\begin{array}{c}\text { \% del total de pares } \\
\text { de patrocinios }\end{array}$ \\
\hline UDI & 7.5 & 3.2 & 1.7 & 3.7 & 1.5 & 3.4 & 2.5 & 0.9 & $\mathbf{2 4 . 4}$ \\
RN & & 5.2 & 1.4 & 3 & 1.4 & 3 & 2.2 & 0.7 & 20.2 \\
PRI/Ind. & & & 2.9 & 2.4 & 1.3 & 2.3 & 1.7 & 0.8 & 14.6 \\
PDC & & & & 6.2 & 2.3 & 4.8 & 4 & 1.5 & 27.8 \\
PRSD & & & & 3 & 2.5 & 2 & 1.2 & 15.2 \\
PPD & & & & & 6.1 & 4 & 1.6 & 27.7 \\
PS & & & & & & 4.7 & 1.5 & 22.5 \\
PC & & & & & & & 1.9 & 10.0 \\
Total \% & & & & & & & & 100 \\
(N) & & & & & & & & & \\
\hline
\end{tabular}

Fuente: Elaboración propia con datos de la Biblioteca del Congreso (SIL).

Para adentrarnos más en la dinámica de copatrocinios, el cuadro 9 muestra los pares de copatrocinios como porcentaje del total de copatrocinios en los que participó cada partido. Por ejemplo, de los 2561 pares de patrocinios en lo que hubo al menos un diputado de la UDI, un $30.8 \%$ fue con otro diputado de ese partido. Todos los partidos tienen más pares de patrocinios con miembros del mismo partido, lo que no debe sorprender. A su vez, es más probable que los partidos tengan más pares de copatrocinios con diputados de la UDI o del PDC que con diputados del PC solo por el hecho de que hay más diputados de esos partidos que del PC.

Del cien por ciento de los pares de copatrocinios en los que participó algún diputado del PC (1052), en 18.9\% de los casos los pares fueron formados por los propios diputados del PC. Luego, el partido con el que el PC más participó en copatrocinios, respecto al total de patrocinios en los que hubo al menos un diputado del PC, fue el PPD (16.2\%), seguido del Ps (14.9\%) y del PDC (14.8\%). El peso relativo de copatrocinios con diputados de partidos de derecha fue menor 
para el PC que para los partidos de la Concertación, lo que subraya la mayor distancia ideológica del PC con los partidos de la derecha chilena. Como el cuadro 9 muestra el peso de los copatrocinios respecto al total de copatrocinios en los que participó cada partido, el hecho de que el PC copatrocine menos con diputados del PDC que incluso la UDI o RN alimenta sospechas de que, si bien eran parte de la misma coalición electoral, el PDC y el PC no formaron una relación de trabajo sólida y fructífera en el patrocinio de mociones en el Congreso.

Cuadro 9. Copatrocinios como porcentaje del total de pares de copatrocinios de cada partido

\begin{tabular}{lrrrrrrrrr}
\hline & UDI & $R N$ & PRI\&Ind & $P D C$ & $P R S D$ & $P P D$ & $P S$ & $P C$ & Total\%(N) \\
\hline UDI & $\mathbf{3 0 . 8}$ & 13.2 & 7.1 & 15.2 & 6.0 & 13.9 & 10.4 & 3.5 & $100(2561)$ \\
RN & 16.0 & $\mathbf{2 6 . 0}$ & 7.0 & 15.1 & 6.8 & 14.8 & 10.8 & 3.4 & $100(2117)$ \\
PRI/Ind. & 11.9 & 9.7 & $\mathbf{2 0 . 1}$ & 16.3 & 9.0 & 16.0 & 11.6 & 5.5 & $100(1532)$ \\
PDC & 13.3 & 11.0 & 8.5 & $\mathbf{2 2 . 3}$ & 8.2 & 17.1 & 14.2 & 5.3 & $100(2917)$ \\
PRSD & 9.6 & 9.1 & 8.7 & 15.1 & $\mathbf{2 0 . 0}$ & 16.7 & 13.1 & 7.7 & $100(1593)$ \\
PPD & 12.2 & 10.8 & 8.4 & 17.2 & 9.2 & $\mathbf{2 1 . 9}$ & 14.4 & 5.9 & $100(2903)$ \\
PS &. & 9.6 & 7.5 & 17.5 & 8.8 & 17.7 & $\mathbf{2 0 . 9}$ & 6.6 & $100(2366)$ \\
PC & 8,6 & 6.9 & 8.0 & 14.8 & 11.7 & 16.2 & 14.9 & $\mathbf{1 8 . 9}$ & $100(1052)$ \\
\hline Total & & & & & & & & & \\
\hline
\end{tabular}

Fuente: Elaboración propia con datos de la Biblioteca del Congreso (SIL).

Finalmente, evaluamos con instrumentos de análisis de redes la participación de los diputados de los distintos partidos en el patrocinio de mociones. Para ello usamos el software UCINET con el fin de evaluar la densidad y el grado de las relaciones de patrocinios de mociones entre diputados de distintos partidos. Si bien otros trabajos han usado métodos estadísticos más sofisticados que aspiran a explicar los patrocinios de mociones a partir de diversas variables independientes (Alemán \& Calvo, 2013), aquí solo intentamos identificar si los partidos de la Concertación y el PC se comportan como parte de la misma coalición o si responden a sus diferentes militancias partidistas. Por eso hemos recurrido a un método simple y visualmente más poderoso al evaluar la validez de nuestra hipótesis.

La figura 1 muestra un mapa de redes de los patrocinios de los 120 diputados en el periodo. El mapa de redes muestra la cercanía de los diputados a partir de cuántos proyectos patrocinaron en conjunto. Los diputados en el extremo izquierdo del mapa patrocinaron muy pocas mociones, o ninguna, con los diputados del extremo derecho del eje. Como el software UCINET produce el mapa en forma aleatoria, lo hemos ordenado de tal forma que los diputados de la Concertación se ubiquen en el eje izquierdo y los de la Alianza en el derecho. 
La figura 1 destaca a los tres diputados del PC. No debiera sorprender que Carmona, Gutiérrez y Tellier se ubiquen en un extremo en la distribución de diputados de acuerdo a sus copatrocinadores. Pero sí resulta ilustrativo que los diputados del PC no sean los que más a la izquierda se ubican. Hay diputados de la Concertación que patrocinan menos proyectos de ley con diputados de centro y de derecha que los tres comunistas. Ya sea porque patrocinan en general menos proyectos y sus patrocinios tienden a ser solo con otros diputados de izquierda o porque patrocinan menos con diputados con quienes no tienen afinidad ideológica, hay diputados de la Concertación que se ubican más a la izquierda que los tres diputados del PC. Con todo, estos últimos se ubican claramente a la izquierda en la distribución de pares de patrocinios de los 120 diputados de la Cámara en el periodo 2010-2013.

Figura 1. Mapa de redes de patrocinio de mociones de los 120 diputados, 2010-2013

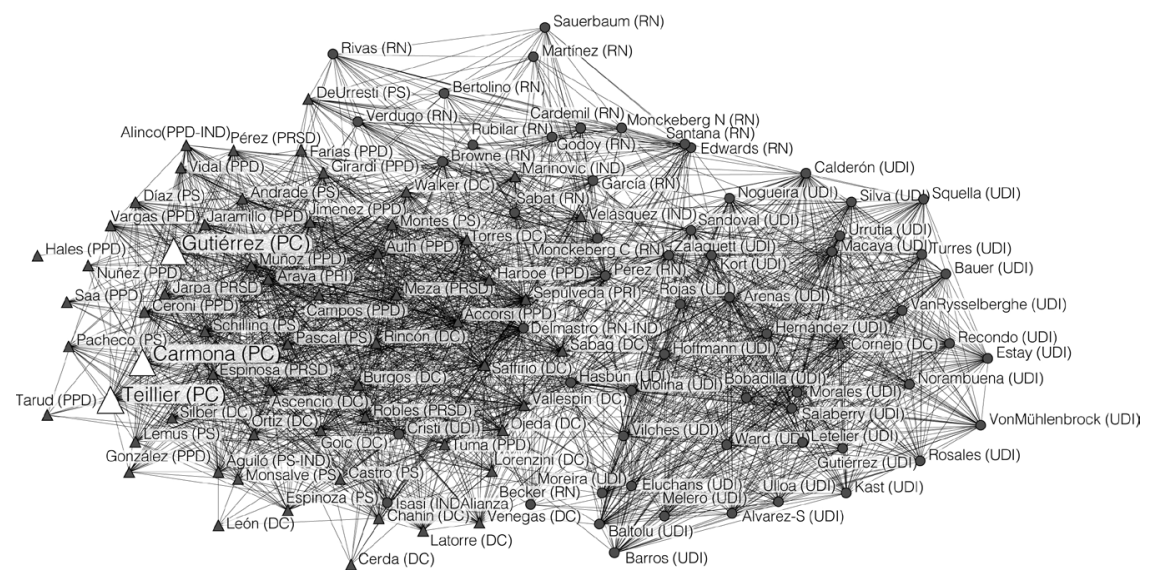

Nota. Diputados de la Alianza en círculos, de la Concertación, PC y otros, en triángulos. Para simplificar la visualización de la figura, solo incluimos líneas para seis o más copatrocinios.

Fuente: Elaboración propia con datos de la Biblioteca del Congreso (SIL).

La figura 2 muestra los pares de patrocinios de los tres diputados del PC con los 56 de la Concertación (cuadro izquierdo) y con los 58 de la Alianza (cuadro derecho). Como se evidencia, los del PC están más cerca de sus pares de la Concertación que de los de la Alianza en sus patrocinios. Es innegable que los diputados del PC aparecen en la órbita de la Concertación si es que se les mira desde la vereda de la coalición derechista Alianza. 
Figura 2. Mapa de redes de patrocinio de mociones por militancia partidista de diputados PC y de la Concertación y Alianza, 2010-2013

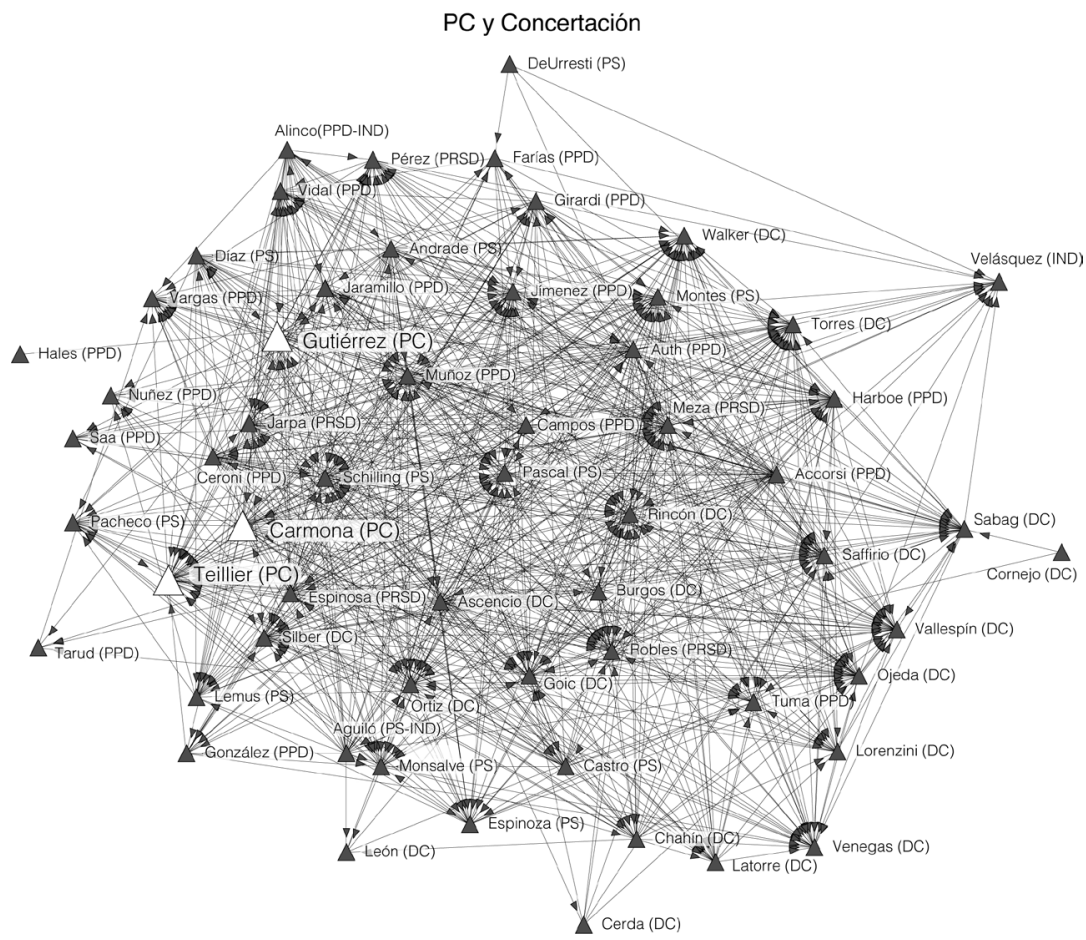

PC y Alianza

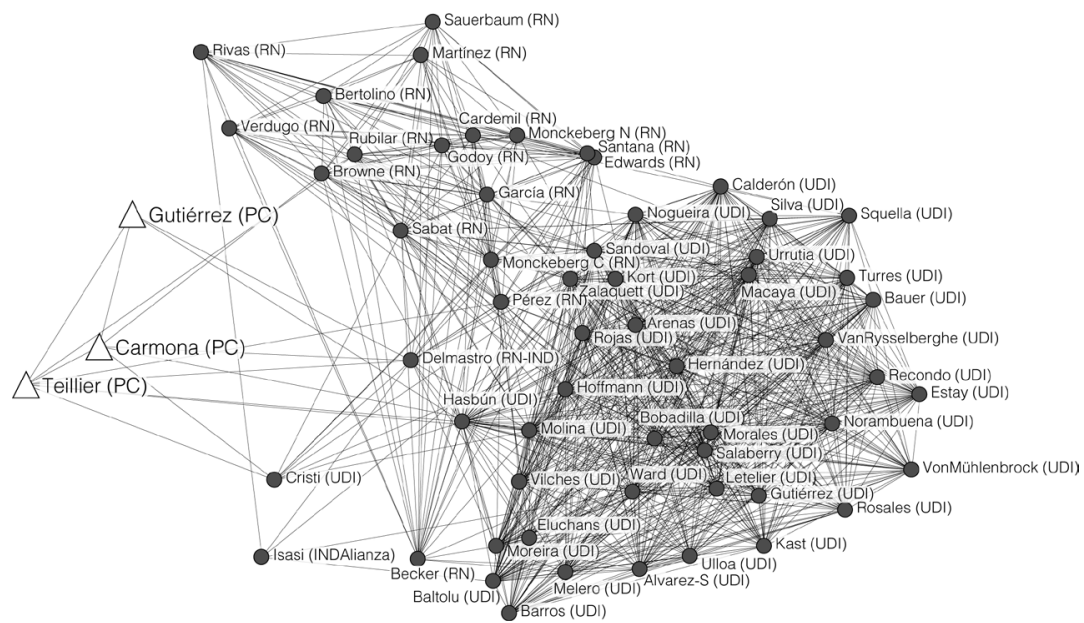

Nota: Diputados de la Alianza en círculos, de la Concertación y del PC en triángulos.

Para simplificar la visualización de la figura, solo incluimos líneas para seis o más copatrocinios.

Fuente: Elaboración propia con datos de la Biblioteca del Congreso (SIL). 
Para explorar más profundamente sobre la relación que existe entre los diputados del PC y los de los otros partidos de la Concertación, la figura 3 muestra los pares de patrocinios entre los tres del PC y los 19 del PDC y entre los del PC y los 37 de los partidos de izquierda de la Concertación (PS, PPD y PRSD).

Figura 3. Mapa de redes de patrocinio de mociones entre diputados del PC, DC y de partidos de izquierda de la Concertación 2010-2013
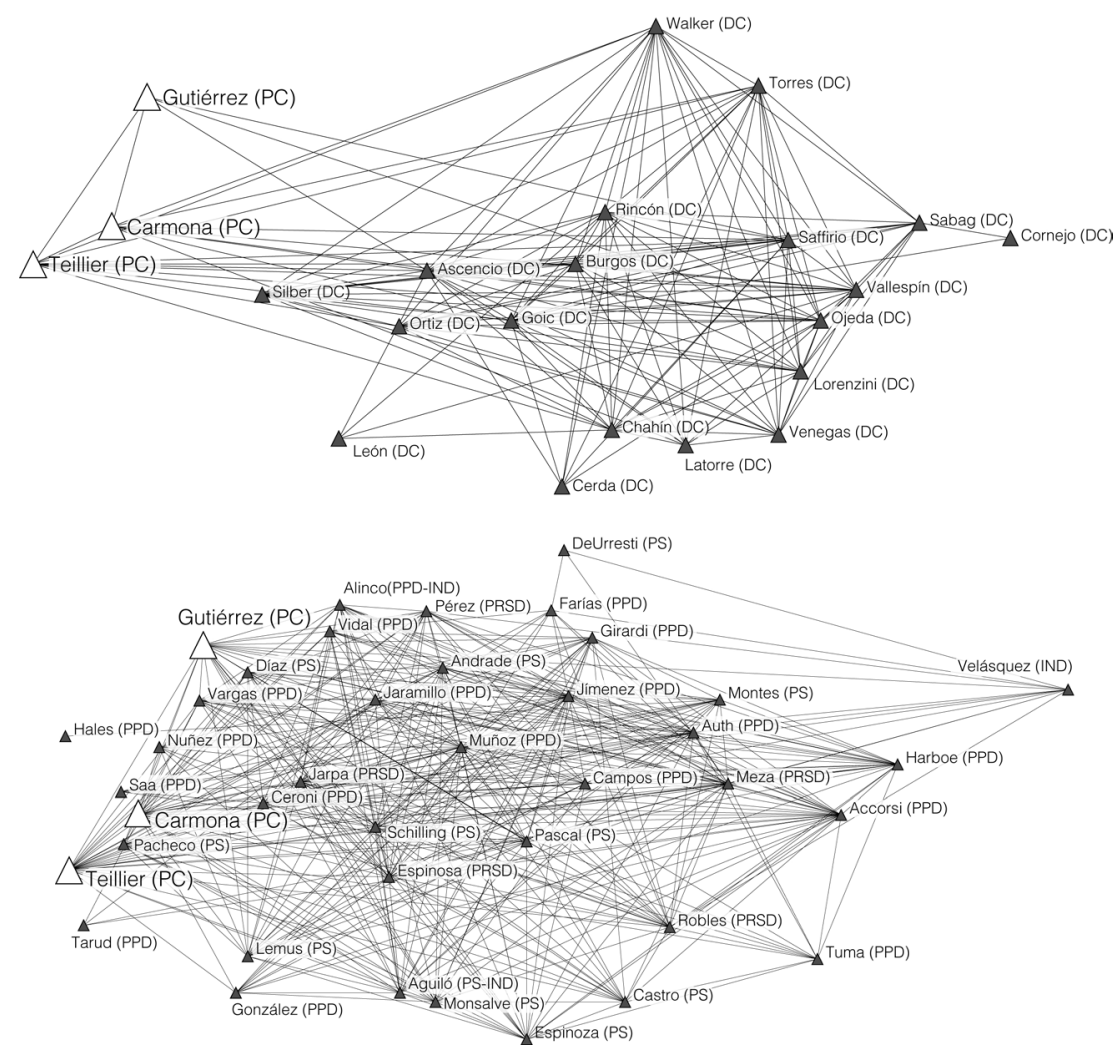

Nota: Para simplificar la visualización de la figura, solo incluimos líneas para seis o más copatrocinios.

Fuente: Elaboración propia con datos de la Biblioteca del Congreso (SIL).

Hay una distancia mayor entre el PDC y el PC que entre los diputados de los partidos de izquierda de la Concertación y los tres del PC en el copatrocinio de mociones. Mientras los tres del PC se ubican a la izquierda de todos los del PDC, hay diputados de partidos de izquierda de la Concertación que se ubican en posiciones más extremas que el PC en lo que toca a patrocinio de mociones. 
Luego, si bien pudiéramos sospechar que los diputados del PC se comportan de forma más cercana al promedio de los de los partidos de izquierda de la Concertación, la distancia entre los del PC y el PDC es notoria.

Figura 4. Mapa de redes en patrocinio de mociones entre diputados de la Alianza, DC y de partidos de izquierda de la Concertación, 2010-2013

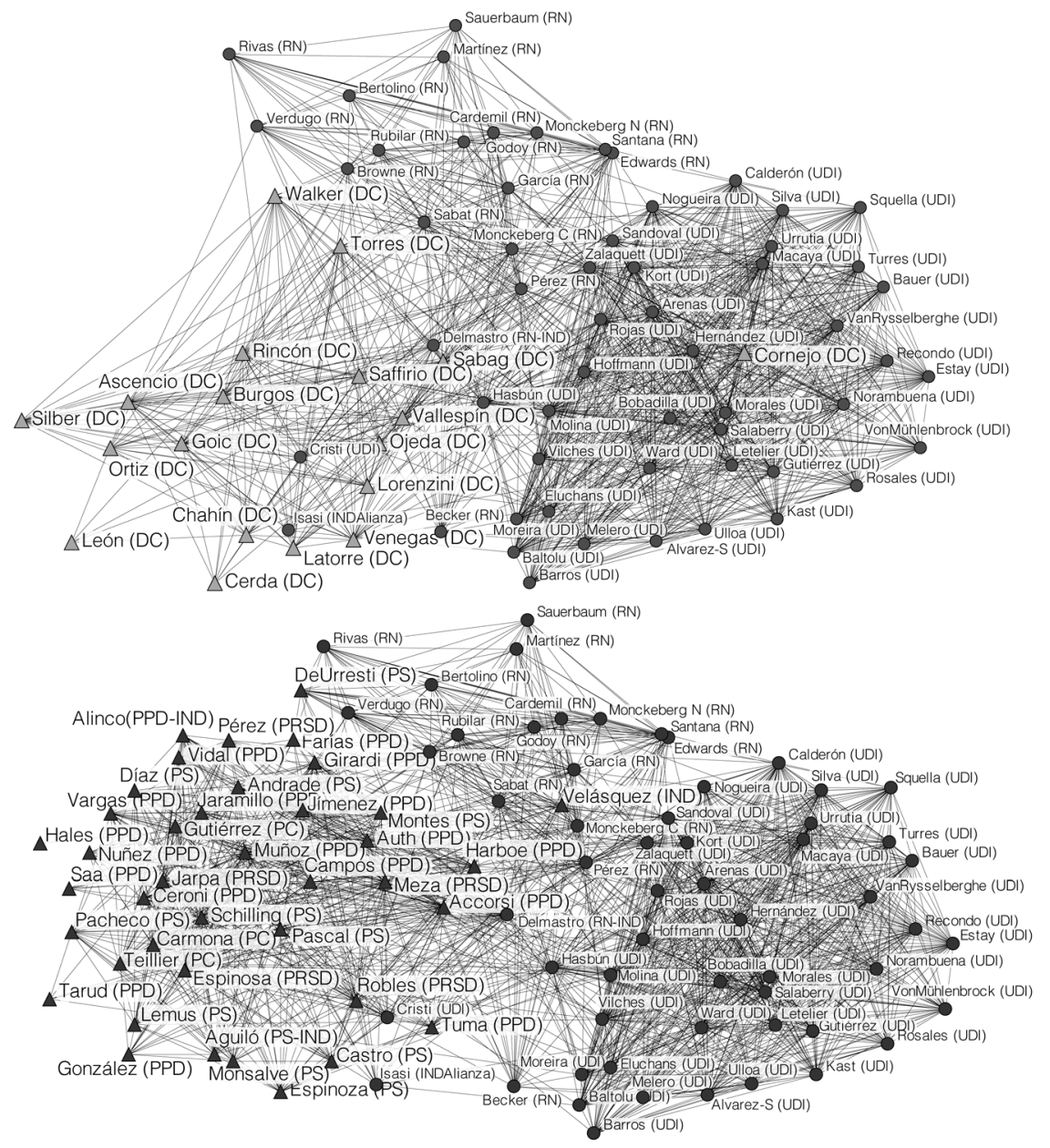

Nota: Diputados de la Concertación, en triángulos; y los de la Alianza, en círculos.

Fuente: Elaboración propia con datos de la Biblioteca del Congreso (SIL).

Finalmente, la figura 4 muestra unos mapas de redes que contrastan la cercanía en los copatrocinios de mociones entre los 19 diputados del PDC y los 
37 de los partidos de izquierda de la Concertación con los 58 diputados de la Alianza. Si bien los diputados del PDC se ubican menos a la izquierda que sus pares del PS, PPD y PRSD, hay una cercanía similar entre los diputados más centristas del PDC y de los partidos de izquierda de la Concertación con los de la Alianza. A diferencia de lo que ocurre entre los diputados del PC y de la Alianza — donde los tres del PC se ubican a la izquierda de todos los de la Alianza—hay diputados de este segundo partido que, en el copatrocinio de mociones, se ubican a la izquierda de los más moderados del PS, PPD y PRSD.

La figura 4 confirma que, a partir del análisis de redes, podemos identificar diferencias evidentes en el comportamiento del pC, en lo que a copatrocinios de proyectos de ley respecta, y de los diputados de la Concertación. Aunque los diputados del PC se comportan de forma similar que los más izquierdistas de la Concertación, el PC en general se ubica bastante más a la izquierda que los diputados del PDC y que los moderados de los tres partidos de izquierda de la Concertación. Esto descarta nuestra hipótesis de trabajo. Si bien formaron una coalición electoral para la contienda de 2009, el PC y los partidos de la Concertación respondieron a intereses distintos en el patrocinio de mociones durante el cuatrienio de Piñera. Mientras los partidos de la Concertación mostraron más amplitud en el eje izquierda-derecha, los tres diputados del PC se comportaron marcadamente más izquierdistas en sus asociaciones con otros diputados para patrocinar proyectos de ley.

\section{Conclusiones}

$\mathrm{Al}$ evaluar el patrocinio de mociones por la militancia partidista de los miembros de la Cámara de Diputados entre 2010 y 2013, evaluamos si el pacto electoral creado por la Concertación y el PC devino en la formación de una coalición política de oposición en el periodo 2010-2014. Analizando los patrocinios de mociones, encontramos que, si bien el PC está más cerca de los partidos de la Concertación que de los de la Alianza, hay una mayor diferencia entre el PC y el PDC que entre el PDC y los partidos de la Alianza.

Aunque formaron una coalición electoral en 2009 - y a partir de marzo de 2014 son parte de la misma coalición de gobierno- el pC y la Concertación no se comportaron como una coalición política de oposición durante el periodo 2010-2014, al menos en lo que a patrocinio de mociones se refiere. De esta forma, al menos en esta dimensión, no podemos hablar de que el pacto electoral formado entre la Concertación y el PC en 2009 se consolidó como una coalición de oposición durante el gobierno aliancista de Sebastián Piñera. 


\section{Referencias}

Alemán, E. (2009). Institutions, Political Conflict and the Cohesion of Policy Networks in the Chilean Congress, 1961-2006. Journal of Latin American Studies, 41(03), 467-491.

Alemán, E. \& Calvo, E. (2013). Explaining Policy Ties in Presidential Congresses: A Network Analysis of Bill Initiation Data. Political Studies, 61(2), 356-377.

Aleman, E. \& Saiegh, S. (2007). Legislative Preferences, Political Parties, and Coalition Unity in Chile. Comparative Politics, 39(3), 253-272.

Alemán, E. \& Tsebelis, G. (2012). Partidos Políticos y Coaliciones de Gobierno en las Américas. Revista Política, 50(2), 5-32.

Blofield, M. H. \& Haas, L. (2005). Defining a Democracy: Reforming the Laws on Women's Rights in Chile, 1990-2002. Latin American Politics and Society, 47(3), 35-68.

Carey, J. M. (2007). Competing Principals, Political Institutions, and Party Unity in Legislative Voting. American Journal of Political Science, 51(1), 92-107.

Carey, J. M. (2002). Parties, Coalitions, and the Chilean Congress in the 1990s. En Scott Morgerstern, S. \& Nacif, B. (Eds.). Legislative Politics in Latin America (pp. 222-253 ). Nueva York: Cambridge University Press.

Chasquetti, D. (2001). Democracia, multipartidismo y coaliciones en América Latina: evaluando la dificil combinación. Montevideo: Cauce.

Colomer, J. M. \& Martinez, F. (1995). The Paradox of Coalition Trading. Journal of Theoretical Politics, 7(1):41-63.

Contreras, G., Espinoza, A. \& Perelló, L. (2012). El Partido Comunista de Chile en las elecciones municipales 1992-2008. En Morales. M. \& Navia, P. (Eds.). Democracia Municipal en Chile, 1992-2012 (pp. 219-240). Santiago: Ediciones Universidad Portales.

Cox, G. (2004). La coordinación estratégica de los sistemas electorales del mundo. Hacer que los votos cuenten. Barcelona: Gedisa.

Cox, G. W. \& McCubbins, M. D. (2007). Legislative Leviathan: Party Government in the House. Nueva York: Cambridge University Press.

Cox, G. W. \& McCubbins, M. D. (2005). Setting the Agenda: Responsible Party Government in the US House of Representatives. Nueva York: Cambridge University Press. 
Crisp, B. F., Escobar-Lemmon, M. C., Jones, B. S., Jones, M. P. \& Taylor-Robinson, M. M. (2004). Vote-Seeking Incentives and Legislative Representation in Six Presidential Democracies. Journal of Politics, 66(3), 823-846.

Figueiredo, A. C. \& Limongi, F. (2000). Presidential Power, Legislative Organization, and Party Behavior in Brazil. Comparative Politics, 32(2), 151.

Golder, S. N. (2006). Logic of Pre-Electoral Coalition Formation (Parliaments and Legislatures). Columbus: Ohio State University Press.

Laver, M. \& Shepsle, K. A. (1996). Making and Breaking Governments. Cabinets and Legislators in Parliamentary Democracies. Nueva York: Cambridge University Press.

Mainwaring, S. (1993). Presidentialism, Multipartism, and Democracy: The Difficult Combination. Comparative Political Studies, 26(2), 198-228.

Mainwaring, S. \& Shugart, M. S. (Eds.). (1997). Presidentialism and Democracy in Latin America. Nueva York: Cambridge University Press.

Navia, P. (2005). Transformando votos en escańos: leyes electorales en Chile, 1833-2003. Política y Gobierno, 12(2), 233-276.

Riker, W. H. (2001). Teoría de juegos y de las coaliciones políticas. En Batlle, A. (Ed.). Diez textos básicos de ciencia politica (pp. 151-169). Barcelona: Ariel.

Rocca, M. S. \& Sanchez, G. R. (2007). The Effect of Race and Ethnicity on Bill Sponsorship and Cosponsorship in Congress. American Politics Research, (36), 130-152.

Siavelis, P. M. (2005). Electoral System, Coalitional Disintegration, and the Future of Chile's Concertacion. Latin American Research Review, 40(1), 56-82.

Toro Maureira, S. (2007). Conducta legislativa ante las iniciativas del Ejecutivo: unidad de los bloques políticos en Chile. Revista de Ciencia Politica (Santiago), 27(1), 23-41.

Tsebelis, G. (2002). Veto Players How Political Institutions Work. Princeton: Princeton University Press.

Recibido el 6 de enero de 2015. Aceptado el 13 de enero de 2017. 